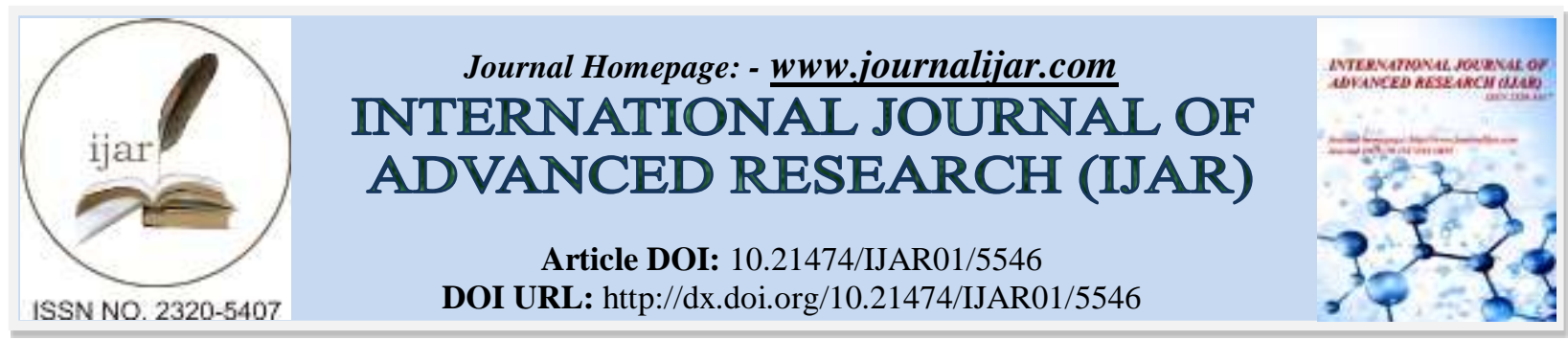

RESEARCH ARTICLE

\title{
GEOTECHNICAL BEHAVIOUR AND TREATMENT OF VARIOUS EXPANSIVE SOIL OF RAJASTHAN.
}

\section{Puneet Hiranandani $^{1}$, Ankit Laddha ${ }^{2}$, Sumer Singh ${ }^{3}$ and Dr. D. G. M. Purohit ${ }^{4}$.}

1. Lecturer, Dept. of Civil Engineering, Govt. Polytechnic College, Jodhpur, Rajasthan, India.

2. Asst. Professor, Dept. of Civil Engineering, Jodhpur Institute of Engineering and Technology, Jodhpur, Rajasthan, India.

3. M.E. Scholar, Dept. of Civil Engineering, M.B.M. Engineering College, J.N.V. University, Jodhpur, Rajasthan, India.

4. Professor, Dept. of Civil Engineering, M.B.M. Engg. College, J.N.V. University, Jodhpur, Rajasthan, India.

\section{Manuscript Info}

(..........................

Manuscript History

Received: 05 August 2017

Final Accepted: 07 September 2017

Published: October 2017

Key words:-

Lime Treatment, Expansive soil.

\section{Abstract}

Expansive soils shrink and swell with wetting and drying. The shrinkswell capacity of expansive soilscan result in differential movement beneath foundations. Expansive soils are soils which swell on exposure to moisture. The occurrence of volume change in soil can cause severe damage to the structure. Irrespective of high swelling potential, if the moisture content of the clay remains unchanged, there will be no volume change, structures founded on clays with constant moisture content will not be subject to movement caused by heaving. When the moisture content of the clay is changed, volume expansion both in vertical and horizontal direction will take place. Complete saturation is not necessary to accomplish swelling, slight change of moisture content, in the magnitude of only 1 to 2 percent, is sufficient to cause detrimental swelling. Since the expansive soil is not best suited for construction thus it becomes necessary to improve its engineering properties and thus making it more stable. For this, use of CNS and MSM technologies is significant. Under-ream pile foundation should be used for construction on expansive soils. Lime is used most frequently in treatment of expansive soils. Fly-ash is also a good and cheap substitute for treatment of expansive soils if easily available in vicinity. The present research work in this paper is deals with the occurrence of expansive soil, damage to foundation from expansive soils, treatment of expansive soils, use of lime treatment effects on geotechnical behavior of expansive soils and finally the conclusion.

Copy Right, IJAR, 2017,. All rights reserved.

\section{Introduction:-}

Expansive soils are highly problematic soils and cause damage to structures founded in them because of their potential to react to changes in moisture regime. They swell when they imbibe water and shrink when water evaporates from them. Because of the alternate swelling and shrinkage of these soils, civil engineering structures such as foundations, retaining walls, pavements, canal beds and linings founded in these soils get severely cracked,

Corresponding Author:- Puneet Hiranandani.

Address:- Lecturer, Dept. of Civil Engineering, Govt. Polytechnic College, Jodhpur, Rajasthan, India. 
resulting in a huge financial loss. Millions of rupees in Rajasthan and India are spent every year to address the damage caused by these soils.

Expansive soil will also exert pressure on the vertical face of a foundation, basement or retaining wall resulting in lateral movement. Shrink-swell soils which have expanded due to high ground moisture experience a loss of soil strength or "capacity" and the resulting instability can result in various forms of foundation problems and shape failure. Expansive soil should always be a suspect when there is evidence of active foundation movement.In order for expansive soil to cause foundation problems, there must be fluctuations in the amount of moisture contained in the foundation soils. If the moisture content of the foundation soils can be stabilized, foundation problems can often be avoided.

\section{Occurrence and Properties:-}

The expansive soils can be found throughout the world and hence the problem of expansive soil is wide spread. In India, large tracts are covered by expansive soils known as black cotton soils, referred to as "Regur". The major area of their occurrence is the South Vindhyachal range covering almost the entire Deccan Plateau. These soils cover an area of about 2,00,000 square miles and thus form about $20 \%$ of the total area of India.Expansive soils have inherent property of shrinking when it is dried and swelling when water is absorbed as shown in figure 1.

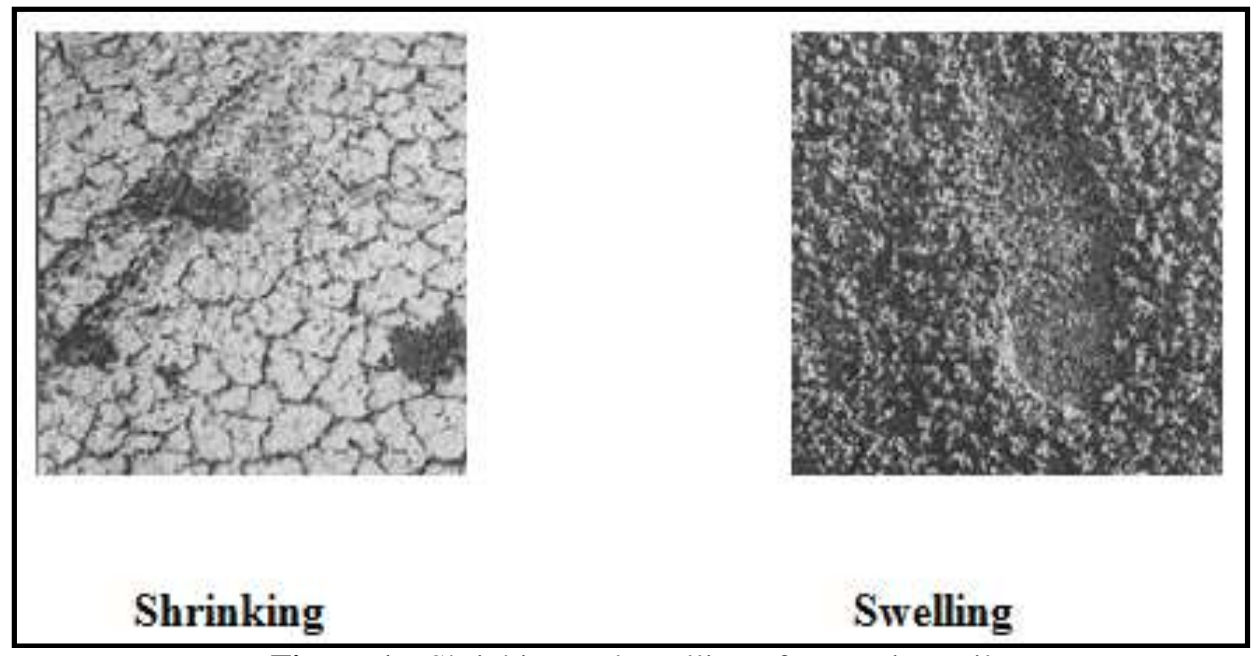

Figure 1:- Shrinking and swelling of expansive soil

In Western Rajasthan, previously it seems that only dune sand is present up to great depth or there is some sand stone etc. However, during construction of Rajasthan Canal (Presently Indira Gandhi Nahar) project, it was observed that bentonite is present below the dune sand or at depth when canal is in cutting. This causes swelling (i.e. volume change) and hence there are cracks in the lining of canal. Swelling soil was observed not only in Jaisalmer (Ramgarh, Pokhran, etc.) but also in Barmer district, Pali district (Jetpur), Nagaur district, Jodhpur district, Bhopalgarh etc. Many research scholars have worked on expansive soils such as Jones \& Holtz (1973), Chan (1975), Mathur (1995) and Pandey (1997). The bentonite found in the Rajasthan region of India is different from the bentonite available in rest of world due to the chemical composition and of high-iron content which gives them their darken colour. Due to the very fine particle size, this bentonite shows extra-ordinary swelling capacity and bonding powers. This difference makes the bentonite to more useful in various work industries.

Properties of expansive soil: Due to the presence of imbalance electrical charge and cation exchange capacity produced by sodium-based montmorillonite the expansive bentonite soil swells. Replacing the sodium ions by inorganic compounds, which may produce such type of cation having less ion exchange capacity and also form a balanced electrical charge in soil structure, can reduce this expansion. Replacement of monovalent sodium by calcium ion may lead to a marked reduction in diffuse double layer thickness leading to decrease in liquid limit, plastic limit and swelling pressure. Keeping this aspect in view, an attempt has been made to study the alteration brought out by dune sand and gypsum mixture. Therefore, tests have been conducted on bentonite soil, obtained from different parts of Rajasthan, mixed with different percentage of dune sand and gypsum to study the effects of mixtures on swelling pressures of expansive soils. Also effects of variation of densities are studied in view of change 
in swelling pressure. Few soil samples from various parts of Rajasthan were analyzed and various properties of these soils such as liquid limit, plastic limit, plasticity index, shrinkage limit, grain size distribution, unconfined compressive strength, shear properties and free swell index were analyzed in laboratory as per various IS (Indian Standard) codes. These are listed as Table 1 and swelling pressure of soils at various densities are listed in table 2.

Table 1:- Properties of various swelling soils of Rajasthan.

\begin{tabular}{|c|c|c|c|c|c|}
\hline \multirow{2}{*}{ Properties } & \multicolumn{5}{|c|}{ Locations of Swelling Soil under case study } \\
\hline & Jaisalmer & Balotra & Merta & Pali & Kolayat \\
\hline Liquid limit \% & 190 & 85.0 & 105.0 & 100.0 & 50.0 \\
\hline Plastic limit \% & 45.0 & 44.0 & 50.0 & 50.0 & 23.0 \\
\hline Plastic index & 14.50 & 41.0 & 55.0 & 50.0 & 27.0 \\
\hline Shrinkage limit \% & 15.3 & 23.7 & 20.2 & 20.0 & 25.0 \\
\hline Sand $\%$ & 3.0 & 2.0 & 5.0 & 7.0 & 12.0 \\
\hline$\%$ passing 75 micro sieve & 97.0 & 98.0 & 95.0 & 93.0 & 88.0 \\
\hline Silt percentage & 28.0 & 79.0 & 41.0 & 66.0 & 53.0 \\
\hline Clay \% & 69.0 & 19.0 & 54.0 & 27.0 & 35.0 \\
\hline Specific gravity & 2.60 & 2.70 & 2.69 & 2.69 & 2.69 \\
\hline Unconfined C- strength $\left(\mathrm{kN} / \mathrm{m}^{2}\right)$ & 180.8 & 120.5 & 127.5 & 125.0 & 90.2 \\
\hline Cohesion $\mathrm{Cu}\left(\mathrm{kN} / \mathrm{m}^{2}\right)$ & 75.5 & 54.0 & 60.2 & 59.5 & 43.2 \\
\hline Angle of internal friction & 21.0 & 25.2 & 22.0 & 22.2 & 28.3 \\
\hline Free swell index & $690 \%$ & $75 \%$ & $108 \%$ & $99 \%$ & $58 \%$ \\
\hline Soil group & $\mathrm{CH}$ & $\mathrm{CH}$ & $\mathrm{CH}$ & $\mathrm{CH}$ & $\mathrm{CH}$ \\
\hline
\end{tabular}

Table 2:- Swelling pressure $(\mathrm{kN} / \mathrm{m} 2)$ of soils at various densities

\begin{tabular}{|l|l|l|l|l|l|}
\hline Density $\left(\mathrm{gm} / \mathrm{cm}^{3}\right)$ & Jaisalmer & Balotra & Merta & Pali & Kolayat \\
\hline 1.45 & 195.0 & 30.2 & 43.7 & 45.2 & 21.3 \\
\hline 1.55 & 270.0 & 50.7 & 65.5 & 67.3 & 41.2 \\
\hline 1.65 & 325.0 & 81.0 & 100.2 & 103.5 & 61.3 \\
\hline 1.75 & 375.0 & 110.2 & 120.3 & 123.5 & 75.5 \\
\hline 1.85 & 395.0 & 120.7 & 129.7 & 131.7 & 85.2 \\
\hline 1.95 & 442.0 & 135.3 & 145.3 & 147.2 & 101.3 \\
\hline
\end{tabular}

\section{Need of Treatment:-}

Soils are composed of a variety of materials, most of which do not expand in the presence of moisture. However, a number of clay minerals are expansive. These include: smectite, bentonite, montmorillonite, beidellite, vermiculite, attapulgite, nontronite, illite and chlorite. There are also some sulfate salts that will expand with changes in temperature. When a soil contains a large amount of expansive minerals it has the potential of significant expansion. When the soil contains very little expansive minerals it has little expansive potential. When expansive soils are present they will generally not cause a problem if their water content remains constant. The situation where greatest damage occurs is when there are significant or repeated moisture content changes.

Expansive soil exhibit volume change due to change in soil moisture. Characteristic experience or swelling materials are highly plastic clays and clay shales that often contain colloidal clay minerals such as montmorillonite. Since expansive soils have a tendency to change their volume to a large extent, they cause heavy distress to engineering constructions. Thus there is a need of treatment of expansive soil. The large scale building distress, due to expansive shrinking nature of expansive soil, can be prevented by either obstructing the soil movement and reducing the swelling pressure of soil or making the structure sufficiently resistant to damage from soil movement. For treatment of expansive soils we mainly use lime-treatment method. Now days we also use CNS (Cohesive-Non-Swelling) and MSM (Mechanically Stabilized Mix) technologies. Addition of gypsum also leads to reduction of swelling pressure of expansive soil. In foundation construction on expansive soil under-reamed pile foundations have been successfully used in India for more than two decades and have been standardized for general use by the National Building Code of India in 1970. 


\begin{abstract}
Damage to Structures:-
Type of damages:- Damages sustained by structures include: distortion and cracking of pavements and on-grade floor slabs; cracks in grade beams, walls, and drilled shafts; jammed or misaligned doors and windows; and failure of steel or concrete plinths (or blocks) supporting grade beams. Lateral forces may lead to buckling of basement and retaining walls, particularly in overconsolidated and non-fissured soils. The magnitude of damages to structures can be extensive, impair the usefulness of the structure, and detract aesthetically from the environment. Maintenance and repair requirements can be extensive, and the expenses can grossly exceed the original cost of the foundation.
\end{abstract}

Occurrence of damages:- Damages can occur within a few months following construction, may develop slowly over a period of about 5 years, or may not appear for many years until some activity occurs to disturb the soil moisture. The probability of damages increases for structures on swelling foundation soils if the climate and other field environment, effects of construction, and effects of occupancy tend to promote moisture changes in the soil.

Mitigation Measures:- The best way to avoid damage from expansive soils is to extend building foundations beneath the zone of water content fluctuation. The reason is twofold: first, to provide for sufficient skin friction adhesion below the zone of drying; and, second, to resist upward movement when the surface soils become wet and begin to swell. Successive drought years have demonstrated that the zone of seasonal fluctuation can extend much deeper than previously believed. Piers extending to depths of six feet can withstand normal annual fluctuations, but do not appear adequate when taken over the long haul, such as a two-year drought followed by an extremely wet year. Another way of mitigating expansive soil problems is to collect surface runoff and to limit surface infiltration during the rainy winter months.

\title{
Treatment of Expansive Soils:-
}

Analysis and assessment of expansive soils is of utmost importance while founding the structures, as these soils undergo large volumetric changes even due to small fluctuations in water content. The volumetric changes are very large in magnitude and they are responsible for distress of structures. The amount of damage caused by expansive soils is alarming. Estimated average annual loss in the world, attributed to expansive soil movement is approximately 1, 05,988 millions of rupees, which exceeds the combined average of annual damages from floods, hurricanes, earthquakes and tornados. Hence it becomes necessary to treat the expansive soils to enrich its engineering properties. According to the characteristics and properties of swelling soils, various important techniques, that has to be adopted, while constructing a foundation on expansive soils.

The following are the important methods to adopt, while constructing foundations on expansive soils.

1. CNS - MSM Technologies

2. Under-ream pile foundation

3. Lime-treatment of expansive soils

4. Fly-ash treatment of expansive soils.

5. Chemical treatment of expansive soils

6. Moisture control.

\section{Lime Treatment Effects on Geotechnical Properties of Expansive Soils:-}

In this paper we study about expansive soil treated with lime. To treat the expansive soil, lime treatment is most preferable. Lime treatment is done by adding lime to a soil. It is useful for treatment of clayey soils. When lime reacts with soil, there is exchange of cation in the adsorbed water layer and a decrease in plasticity of the soil occurs. The resulting material is more friable than the original clay, and is therefore, more suitable as subgrade.

Lime is produced by burning of lime stone in kilns. The quality of lime obtained depends upon the parent material and the production process. There are basically 5 types of limes:

1. High calcium, quick lime $(\mathrm{CaO})$

2. Hydrated, high calcium lime $[\mathrm{Ca}(\mathrm{OH}) 2]$

3. Dolomitic lime $(\mathrm{CaO}+\mathrm{MgO})$

4. Normal, hydrated dolomitic lime $[\mathrm{Ca}(\mathrm{OH}) 2+\mathrm{MgO}]$

5. Pressure, hydrated dolomitic lime $[\mathrm{Ca}(\mathrm{OH}) 2+\mathrm{MgO} 2]$.

The quick lime is more effective as stabilizer than the hydrated lime, but the latter is more safe and convenient to handle. Generally, the hydrated lime is used. It is also known as "slaked lime". The higher the magnesium content of the lime, the less is the affinity for water and the less is the heat generated during mixing. 
The amount of lime required for treatment varies between 2 to $10 \%$. However, if the lime is used only to modify some of the physico-chemical characteristics of the soil, the amount of lime is about 1 to $3 \%$. Figure 2 showing expansive soil treated by lime stabilization.

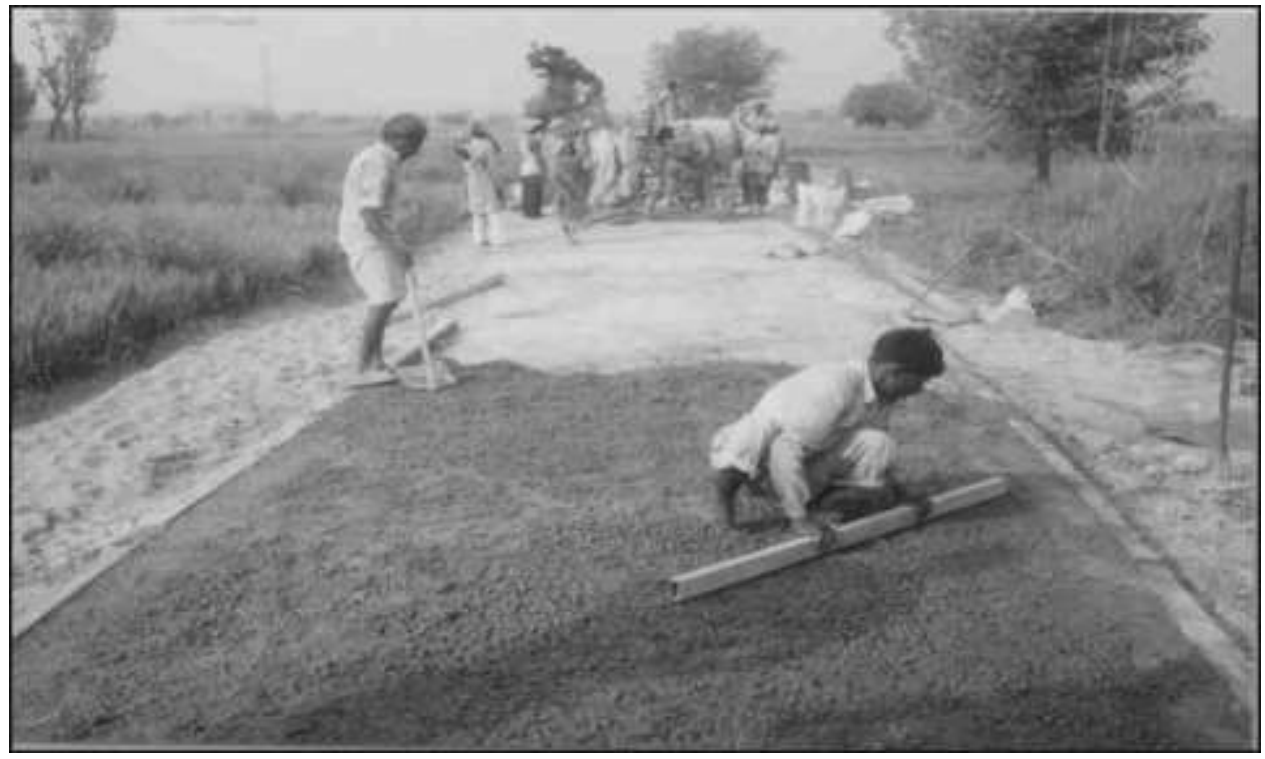

Figure 2:- Lime Stabilization Method

\section{Chemical \& Physical Changes in Lime Stabilization:-}

When lime reacts with wet soil, it alters the nature of the adsorbed layer by Base Exchange. Calcium ions replace the sodium or hydrogen ions. The double layer is usually depressed due to an increase in the cation concentration. However, sometimes the double layer may expand due to high $\mathrm{pH}$ value of lime. Lime reacts chemically with available silica and alumina in soils. Natural cement composed of calcium alumino silicate complexes is formed, which causes a cementing action. The reaction depends upon the effective concentration of the reactants and temperature.

In lime stabilization the liquid limits of the soil generally decreases but the plastic limit increases. Thus, the plasticity index of the soil decreases.

$\mathrm{Ip}=\mathrm{Wl}-\mathrm{Wp}$

Ip = plasticity index

$\mathrm{Wl}=$ liquid limit

$\mathrm{Wp}=$ plastic limit

The soil becomes more friable and markable. The strength of the lime-stabilised soil is generally improved; it is partly due to a decrease in the plastic properties of the soil and partly due to formation of cementing material. Increase in the unconfined compressive strength is sometimes as high as 60 times. The modulus of elasticity of the soil also increases substaintially.

Addition of lime causes a high concentration of calcium ions in the double layer. It causes a decrease in the tendency of attraction of water. Consequently, the resistance of the soil to water adsorption, capillary rise and volume changes on melting or drying is substantially increased. The lime-stabilised bases or sub-bases form a water resistant barrier which steps penetration of rain water. There is an increase in the optimum water content and a reduction in the maximum dry density. In swampy areas where the water content is above the optimum, application of lime to soil helps in drying of the soil. Cyclic freezing and thawing can cause a temporary loss of strength, but because of subsequent healing action, there is no loss of strength in long run. Figure 3 show that lime treatment method. 


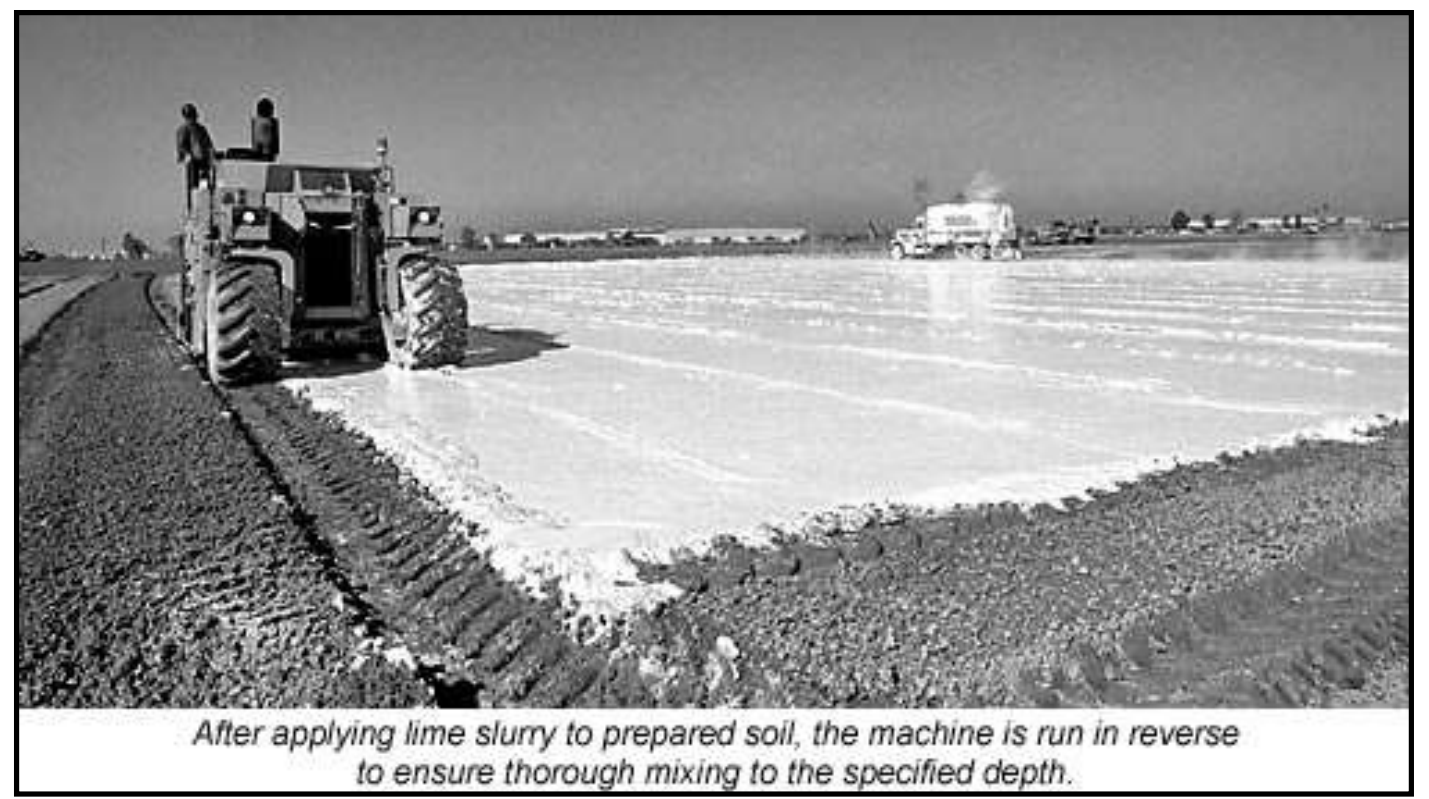

Figure 3:- Lime-treatment method

\section{Construction Methods:-}

The construction of soil-lime bases and sub-bases is done using the following methods:

1. Mix-in-place method: In this method of construction, mixing of soil-lime is done at the place where it would be finally placed. It consists of the following steps :

a) The subgrade is cleared of all undesirable materials such as boulders, debris, stumps. It is then levelled to the required formation level.

b) The levelled subgrade is scarified to a depth equal to proposed thickness of the soil lime.

c) The scarified soil is then pulverized till atleast $80 \%$ of the soil passes $4.75 \mathrm{~mm}$ IS sieve. It can be done either manually or with the help of a machine.

d) The pulverized soil is properly shaped to the required grade and the required quantity of lime is spread uniformly over the surface.

e) The required quantity of water is sprinkled over the surface and wet mixing is done till the mixture has a uniform colour. The surface is then properly graded using towed graders.

f) Compaction is done using suitable methods. After compaction, the surface is properly finished.

2. Plant-mix method: There are two types of plants used in the plant-mix method of construction.

a) Stationary plant: In this method, the excavated soil is transported to a stationary plant located at a suitable place. The required quantity of lime is added to the soil in the plant. Mixing is done after adding water. The time required to obtain a uniform mixture depends upon the type of soil. The mixed material is then discharged into dumper trucks and transported back to the subgrade. It is spread and properly compacted.

The stationary plant is useful for obtaining a uniform mix. In this method, the depth of treatment can be better controlled. However, the method is quite expensive as compared with mix-in-place method.

b) Travelling Plant: A travelling plant can move along the road under construction. The soil, after placement of lime over it, is lifted up by an elevator and discharged into the hopper of the mixer of the traveling plant. Water is added and proper mixing is done. The mix is then discharged on the subgrade and spread by a grader. It is then properly compacted.

The travelling plant method, like stationary plant, is useful for accurate proportioning and uniform mixing. The depth of treatment is also properly controlled and a uniform subgrade surface is attained. However, the initial cost is very high.

\section{Conclusion:-}

Expansive soils, being problematic soils with their innate potential for severe volume changes upon changes in moisture content, need to be treated with special techniques. The following conclusions can be drawn from the present paper:

1. The expansive or shrink-swell soils are a very common cause of foundation problems. 
2. The swelling pressure increases with the increase in dry density and decreases with increase in moulding water content.

3. For undisturbed soil, the swelling pressure can be defined as the pressure required to keep the volume of a soil at its natural dry density constant.

4. To stop the damage due to expansive soils, it becomes necessary to alter its engineering properties.

5. The addition of lime stabilizer was found to decrease the liquid limits, plasticity indices and shrinkage limits.

6. Swelling soils are present in various parts of Rajasthan. The swelling pressure decreases due to addition of gypsum and dune-sand.

7. Deeper foundations are much safer than shallow foundations as they offer more frictional resistance (underream pile foundation should be used for construction on expansive soil).

8. Providing cushions under the foundations can reduce effect of swelling potential on foundation.

9. As moisture changes are responsible for the swelling of expansive soils, it is better to provide moisture barriers around the building area to prevent the percolation of moisture.

10. Some chemicals as calcium chloride, sodium chloride, gypsum, etc. form water proofing agents, when they are mixed with the soil and prevent the access of moisture.

11. Lime is also a good and cheap substitute for treatment of expansive soils if easily available in vicinity.

\section{References:-}

1. Alam Singh "Basic Soil Mechanics and Foundation", CBS Publishers and Distributors, India.

2. Ankit laddha, Dr. DGM Purohit "Stabilization of Fine Sand using Square Pieces of Waste Plastic as Admixture for Construction of Embankments for Road", IJIRSET, Vol. 6, Issue 8, August 2017

3. Behaviour of saturated expansive soil and control methods by Ramanath Keshavarao Katti, Dinesh Ramanath Katti, Anand Ramanath Katti (2002).

4. EJGE, a case study : Structure Damage due to expansive soils presented by Beni Lew. www.ejge.com

5. EJGE, Paper on Characteristics, Problems and Remedies of Expansive Soils of Rajasthan, India by Dr. N.K. Ameta, Dr. D.G.M. Purohit and A.S. Wayal, http:www.ejge.com/2007/ejge paper.html

6. Fly Ash India, 2005, New Delhi, : Stabilization of Expansive Soil using Fly Ash (S. Bhuvaneshwari, R.G. Robinson, S.R. Gandhi)

7. Evaluation of Different Reinforced Subbases on Expansive Soil Subgrades. The $12^{\text {th }}$ International Conference of International Association for Computer Methods and Advances in Geomechanics (IACMAG) 1-6 October, 2008, Goa, India.

8. Sridharan, A. \& Prakash, K. (2000) Classification procedures for expansive soils. Proc. Instn. Civ. Eng. Geotech. Eng. 143, 235-240.

9. Sivapullaiah, P.V.M. Sridharan, A. and Stalin, V.K. Swelling behaviour of soil bentonite mixtures, Canadian Geotechnical Journal, 33, 808 - 814 (1996)

10. Chen, F.H., Foundations on Expansive Soils, Elsevier Scientific Publishing Company, Amsterdam-OxfordNew York, (1981).

11. Chan R.H. (1975) "Foundation on Expansive Soil," 2nd edition. Elsevier Scientific Publishing Company, New York.

12. Chen, F. H. (1988) "The Basic Physical Properties of Expansive Soils", Proc. 3`d Int. Conf. on Expansive Soils, Haifa, Israel.

13. Jones, D.E J., and Holtz, W.G. (1973) "Expansive Soils - The hidden Disaster," Civil Engineering, Vol.43, Nov. 8.

14. Katti, R.K. (1972) "Mechanics of Swelling Soil Media - A Discrete Practical Approach" Keynote address symposium on strength and deformation behaviour of soil, Indian Geotechnical Society, Mysore Centre, Banglore.

15. Katti, R.K. (1979) "Search for Solutions to Problems in Black Cotton Soils". Indian Geotechnical Journal, LG.S. Vol. 9, No. 1

16. Punmia B.C., "Soil Mechanics and Foundation", Laxmi Publications Pvt. Ltd., India.

17. K.R. Arora "Soil Mechanics and Foundation Engineering", Standard Publishers and Distributors, New Delhi.

18. SATYANARAYANA. D (1966): "Swelling pressure and related mechanical properties of black cotton soil", Ph.D. Thesis I.I.Sc., Bangalore. 